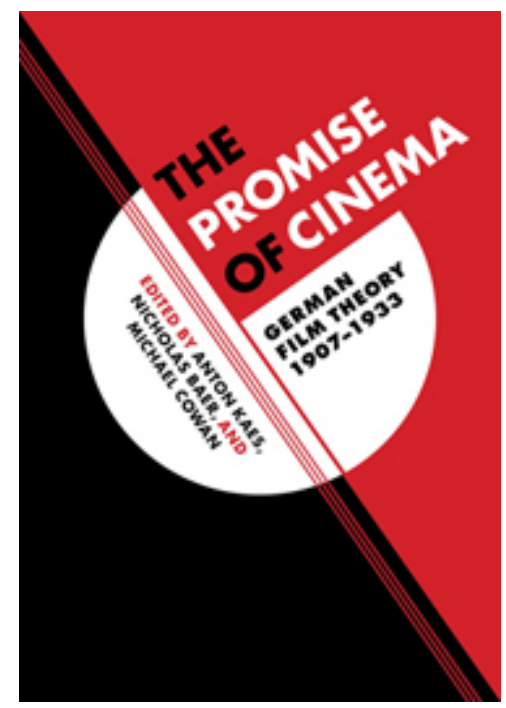

Anton Kaes, Nicholas Baer \& Michael Cowan (toim.) (2016): The Promise of Cinema: German Film Theory, 1907-1933. Oakland: University of California Press. $682 \mathrm{~s}$.

Anton Kaesin, Nicholas Baerin ja Michael Cowanin toimittama, lähes 700-sivuinen 1900luvun alun saksalaisen elokuvateorian antologia The Promise of Cinema: German Film Theory 1907-1933 on laaja läpileikkaus saksankielisessä maailmassa käydystä elokuvakeskustelusta vuodesta 1907, jolloin alkoivat ilmestyä ensimmäiset saksankieliset elokuvalehdet, vuoteen 1933, natsien valtaannousuun. Teos on valtava tiiliskivi. Tekstejä on niin paljon, että niiden mahduttamiseksi yksien kansien sisään on jouduttu turvautumaan hyvin pieneen tekstikokoon, ja siltikin monia tekstejä on jouduttu lyhentämään.

Teoksen ilmeinen esikuva on Richard Abelin alun perin vuonna 1988 julkaistu antologia French Film Theory and Criticism 1907-1939 (johon tekijät viittaavat vain ohimennen alaviitteessä). Abelin tavoin Kaesin, Baerin ja Cowanin teokseen on koottu laajalla skaalalla elokuvaan liittyviä kirjoituksia päiväkohtaisista teksteistä syvempiin analyyseihin ja teoreettisiin visioihin. Mukana on tavanomaisesti julkaistujen tekstien ohella aineistoa esimerkiksi pamfleteista, radiopuheista, luennoista ja jopa päiväkirjamerkinnöistä ja kirjeistä. Myös kirjoittajien joukko on moninainen. Mukana on tunnettuja elokuva- ja kulttuurikeskustelijoita (Rudolf Arnheim, Siegfried Kracauer, Lotte Eisner, Béla Baláz, Walter Benjamin, Theodor Adorno, Georg Lucács, Ernst Bloch), näyttelijöitä, tuottajia, teatteri- ja elokuvaohjaajia ja säveltäjiä (Fritz Lang, Leni Riefenstahl, G. W. Pabst, Billy Wilder, Erich Pommer, Bertolt Brecht, Erwin Piscator, Walther Ruttmann,
Hans Richter, Marlene Dietrich, Emil Jannings, Edmund Meisel, Kurt Weill) ja kirjailijoita (Alfred Döblin, Robert Musil, Heinrich Mann) ja näiden lisäksi monia enemmän tai vähemmän tunnettuja ja osin anonyymeiksikin jääviä kirjoittajia.

Ilmeisin ero Abelin antologiaan nähden liittyy tapaan, jolla aineisto on järjestetty. Abelin teos etenee tiukan kronologisesti, tekstit esitetään siinä järjestyksessä kuin ne on julkaistu. Kaes, Baer ja Cowan ovat päätyneet temaattiseen rakenteeseen siten, että antologia on jaettu kolmeen pääosioon, jotka kukin jakautuvat kuuteen lukuun ja vasta kunkin luvun sisällä artikkelit on järjestetty kronologisesti.

Osiot ovat "Kokemuksen transformaatiot" (Transformations of experience), "Elokuvakulttuuri ja politiikka" (Film culture and politics) ja "Välineen konfiguraatiot" (Configurations of a medium). Ensimmäinen osio keskittyy tapoihin, joilla vuosisadan alun elokuvakatsojat kokivat elokuvan muuttavan tai laajentavan kokemustaan maailmasta: uudenlaiseen näkemisen tapaan, kokemukseen ajasta, tilasta ja ruumiillisuudesta ja laajemmin katsojuuteen ja modernisuuden estetiikkaan. Toisessa osiossa huomion kohteena ovat elokuvan sosiaaliset ja psykologiset ulottuvuudet sekä toisaalta elokuvan suhde urbaaniin massayhteiskuntaan, valtiovaltaan, talouteen, sensuuriin ja propagandaan. Kolmannessa osiossa painopisteenä ovat aikakauden keskeiset tekniset ja esteettiset kysymykset: yhtäältä ekspressionismi ja avantgarde, toisaalta elokuvan ilmaisulliset tekniikat ja äänen läpimurto, elokuva tieteen, kulttuurin 
ja mainonnan välineenä ja lopulta elokuvaan liitetyt tulevaisuuden odotukset.

Kiinnostavampi ero Abelin teokseen liittyy valittuun näkökulmaan, johon myös teoksen rakenne perustuu. Abelin antologian tavoin teos on kyllä läpileikkaus tietyn aikakauden ja kulttuuripiirin elokuvakeskustelusta ja sen teemoista ja kehityksestä, mutta se ei ole vain sitä. Näkökulma käy ilmi jo teoksen otsikosta: toimittajat ovat halunneet painottaa sitä, että aikakauden keskustelussa ei ole kyse vain siitä, mitä elokuva sinänsä on, vaan myös elokuvaan aikalaisten näkökulmasta sisältyneestä "lupauksesta", toisin sanoen sen avaamista mahdollisuuksista, potentiaalista - siitä, mitä elokuva voisi olla tai mitä sen pitäisi olla. Tällä näkökulmalla toimittajat haluavat yhdistää historiallisen keskustelun vahvemmin nykyisen mediakentän kysymyksenasetteluihin. Taustalla on se muutos elokuvan ja visuaalisen kulttuurin asemassa, joka erottaa 1980-luvun lopun 2010-luvun lopusta: digitaalisen median nousu. Kiinnostavaa ei enää olekaan se, mitä "elokuva" aikalaisille merkitsee, vaan mitä heidän aikansa "uusi media" heille merkitsee - ja miten heidän kokemuksensa liittyy nykyiseen kokemukseen median murroksesta.

Yksi kysymyksiä herättävä asia teoksessa on se, missä mielessä ja missä laajuudessa julkaistuista teksteistä voidaan puhua"teoriana". Selvää on se, että monet teksteistä ovat enemmän päiväkohtaisia havaintoja ja kommentteja, joita kirjoittaja ei mitenkään ilmeisesti ole tarkoittanut elokuvan teoriaksi. Toimittajien tavoitteena onkin ollut teorian käsitteen laajentaminen kattamaan klassisen "esteettisen diskurssin" ohella myös monimuotoisen elokuvaa käsittelevien "diskurssien verkoston" (s. 2), toisin sanoen koko sen keskustelukulttuurin, jonka puitteissa elokuvaa koskevat käsitykset (ja käsitteet) saivat muotonsa. Näkemys ei ole ongelmaton - jos kaikki keskustelu on "teoriaa", voidaanko enää puhua teoriasta erityisessä merkityksessä - mutta se on perusteltu ainakin sikäli, että se ohjaa lukijaa tarkastelemaan käsillä olevia tekstejä teorian näkökulmasta. Näin lukija saattaa myös huomata niissä sellaisia "teoreettisia" intuitioita, joita kirjoittaja ei ehkä sellaisiksi ole mieltänyt.

Tällaisiksi intuitioiksi voidaan tulkita esimerkiksi romaanikirjailija (ja sittemmin käsi- kirjoittaja) Hans Heinz Ewersin vuonna 1907 esittämä huomio siitä, että takaperin esitetty elokuva "tekee seurauksesta syyn ja syystä seurauksen" (s. 14), tai taidemaalari ja kriitikko Gustav Melcherin vuonna 1909 esittämä ajatus, että " $[k]$ inematografi on uusi visuaalinen elin, laajennettu ja parannettu silmä" (s. 18). Vastaavia intuitioita ovat myös berliiniläisen lääkärin Eduard Bäumerin vuoden 1911 pohdinnat elokuvasta uudenlaisena havainnon instrumenttina ja sen mahdollisuuksista nopeuttaa aikaa ja näin tehdä näkyväksi ilmiöitä (kuten kasvien kasvua), joita hidas arkihavainto ei voi tavoittaa (s. 80). Näiden pohdintojen yhteydet esimerkiksi ranskalaisten Jean Epsteinin ja Germaine Dulacin ja neuvostoliittolaisen Dziga Vertovin 1920-luvun näkemyksiin ovat ilmeisiä. Hyvin "epsteiniläinen" on myös itävaltalaisen Vicki Baumin modernistinen kuvaus auton merkityksestä elokuvissa: "Auto ei vain ilmesty; se ei ole vain lavaste, vaan pikemminkin tarina itse, draama, impulssi, keskus. Auto viettelee, kidnappaa, pakenee, ajaa takaa, kilpailee, törmää: se pakottaa tahtinsa elokuvaan [...]" (s. 327).

Tekstien näkökulmat elokuvan "lupauksiin" ovat moninaisia. Esteettistä pohdintaa edustavat esimerkiksi Walther Ruttmannin ja Hans Richterin avantgarden traditioon liittyvät pohdinnat liikkeestä, maalaustaiteen ja elokuvan suhteesta ja "absoluuttisesta elokuvasta" tai toisaalta esimerkiksi Béla Balázin, Fritz Langin ja muiden näkemykset mykkäelokuvan estetiikasta. Toisaalta joissain artikkeleissa elokuva on puhtaasti pragmaattinen työkalu. Tällaista näkökulmaa edustaa esimerkiksi poliitikko ja virkamies Wilhelm von Ledebur pohtiessaan elokuvan käyttöä poliisityön ja valvonnan ja välineenä. Kiinnostavia ovat myös spekulaatiot uusista teknisistä tulevaisuuksista, kuten kolmiulotteisuudesta elokuvassa (jota pohtii ensimmäisenä jo vuonna 1914 ohjaaja Max Mack) ja televisiotekniikan mahdollisuuksista.

Kaiken kaikkiaan teos tuo arvokkaan lisän 1900-luvun alun elokuvakulttuuria käsittelevään kirjallisuuteen. Se avaa samanlaisen kurkistusaukon saksalaiseen 1900-luvun alun keskusteluun kuin minkä Abelin antologia teki ranskalaisen elokuvakeskustelun kohdalla. Nimettiin aikakauden keskustelu "teoriaksi" tai ei, niin vähintäänkin voidaan sanoa, että 
keskustelun kokonaisuuden ja erilaisten näkökulmien avaaminen syventää ymmärrystä aikakauden elokuva-ajattelusta ja on sellaisena suositeltavaa luettavaa kenelle tahansa elokuvasta, sen teoriasta tai varhaisesta modernismista kiinnostuneelle.

\section{Antti Pönni}

FL, Metropolia-ammattikorkeakoulu 